INVESTIGACIONES 



\title{
MOVIMIENTO SACERDOTAL ONIS: LA IGLESIA EN EL PERÚ ANTE LAS DEMANDAS DE JUSTICIA SOCIAL (1968-1975)
}

\author{
PRIEST MOVEMENT ONIS: THE CHURCH IN PERU \\ BEFORE SOCIAL JUSTICE DEMANDS (1968-1975)
}

Juan Ramírez Aguilar*

\begin{abstract}
RESUMEN
La presente investigación estudia el proceso histórico de un sector de la Iglesia católica peruana: Movimiento Sacerdotal ONIS. El mencionado Movimiento publicó pronunciamientos y declaraciones a partir de la doctrina social de la Iglesia, mostrando rasgos comunes de la época: lucha contra la pobreza y opción preferencial por los pobres. La estructura de la investigación tiene tres etapas: Post Vaticano II, Movimientos sacerdotales de Latinoamérica y, finalmente, ONIS: doctrina de la Iglesia y praxis. De esta manera, el propósito de la investigación es mostrar que el Movimiento Sacerdotal ONIS mostró una labor pastoral de los sectores populares orientada hacia la justicia social.
\end{abstract}

\section{PALABRAS CLAVE:}

Movimiento Sacerdotal ONIS, doctrina social de la Iglesia, justicia social, Concilio Vaticano II y opción preferencial por los pobres.

\begin{abstract}
The present research studies the historic process of a Peruvian Catholic Church sector: priest movement ONIS. The aforementioned movement published pronouncements and declarations from the social doctrine of the church, expressing common characteristics of the time: fight against poverty and the preferential option for the poor. The structure of the research is a stage post-II Vatican Council, Latin American Priest Movements and finally, ONIS: doctrine of the Church and praxis. In this manner, the purpose of this research is to show that Priest Movement ONIS made known a pastoral work of the popular sectors oriented to social justice.
\end{abstract}

\section{KEYWORDS:}

Priest Movement ONIS, Doctrine Social of the Church, Social Justice, Second Vatican council, preferential option for the poor.

* Docente de la Universidad Ricardo Palma: juanhistoria@hotmail.com 


\section{LA ETAPA POST-VATICANO II}

El concilio Vaticano II generó un despertar de la misión de la Iglesia. Si bien los concilios de Trento y Vaticano I retomaron los planteamientos doctrinales de la Iglesia para responder a los ataques surgidos por los protestantes y los ilustrados, el Vaticano II fue visto por el mundo entero como la esperanza de la Iglesia para asumir su compromiso con la sociedad. Si bien la modernización cambiaba el modo de vida de los hombres, por otra parte había quienes se alejaban de estas posibilidades de progreso, llegando muchos a la pobreza extrema, especialmente en África y Latinoamérica que eran dependientes de los capitales extranjeros.

Se logró con el Vaticano II el diálogo con el mundo moderno. Sus decretos, constituciones y declaraciones son el significado de una Iglesia renovada y que no se mantiene estática ante los cambios producidos. La Iglesia no solo debe estar al tanto de la situación espiritual de sus hijos, sino también la de su situación temporal. Los ciudadanos de la ciudad temporal y de la ciudad eterna están obligados a cumplir con fidelidad sus deberes temporales guiados por el espíritu evangélico. La fe es la base que todo cristiano tiene para cumplir con la vocación de ayudar al prójimo tal como nuestro Señor Jesucristo lo hizo (Gaudium et Spes: $N^{\circ} 43$ ). De esta manera se puede deducir que la Iglesia asume un compromiso con una realidad objetiva que necesita curar sus heridas -como son falta de alimentación adecuada y la carestía de servicios necesarios para tener una vida digna - para que pueda ser signo de vida y de esperanza para un mundo nuevo basado en la justicia social.

Luego del Concilio, hubo muchas interrogantes e inquietudes de los teólogos. Si bien la actitud renovadora de la Iglesia había dado sus primeros pasos, por otra parte había quienes no deseaban cambios. Ramírez sostiene que en la Iglesia siempre habrá discusiones en su seno, pero será en los concilios que encaminen las reformas necesarias teniendo como centro al Evangelio (2013: 182).

La Iglesia no escapa al proceso histórico, es decir, a mediados del siglo $\mathrm{XX}$ se polarizaron las ideologías: comunistas y capitalistas. ¿Pero qué tiene que ver esta polaridad ideológica? Lo cierto es que con el Vaticano II se polarizaron posturas teológicas. Por una parte, se encuentran los conservadores o tradicionalistas $y$, al otro lado, se encuentran los progresistas $\mathrm{O}$ de avanzada.

Esta polarización teológica hizo que en la Iglesia surgiera una etapa de "intranquilidad". Las discusiones podían ser duras por el sector conservador, que ponía mucho énfasis en los dogmas, una Iglesia institucionalizada, jerárquica y privilegiada. Mientras que el sector progresista ponía mucho énfasis en la constitución pastoral Gaudium et spes.

Dentro del debate que generaron los diversos documentos del Vaticano II tenemos a quiénes mostraban una postura teológica pesimista. Según Miret (1966: 89) con el concilio Vaticano II la Iglesia atraviesa una nueva etapa que no será positiva, por el contrario, se está dando un fenómeno distinto en que existe una lucha abierta entre grupos católicos como una guerra sin cuartel a nivel mundial, incluido los países latinos. De mismo modo, el concilio Vaticano II ha generado dentro de la Iglesia intranquilidad, temor y pesimismo entre los propios cristianos. La cristiandad que en otrora estaba robustecida y definida, 
al parecer está declinando (Adolfs, R. 1967: 9).

Hubo quiénes mostraron una visión teológica positiva del Vaticano II. Según Muckenhirn (1969: 9) el concilio Vaticano II ha generado una etapa revolucionaria del hombre en que es motivado por el mensaje de Cristo a cumplir la voluntad del Padre. La renovación traída por el concilio Vaticano II no puede ser a medias ni tranquila. Los mandatos del Vaticano II no pueden postergarse porque sería fracasar al amor de Cristo. Así, la renovación dada por el Concilio debe llegar a ser plena y no una renovación incompleta, destacando la presencia renovadora de la Iglesia en su historia. El principal motor de cambio se enfoca al hombre como agente de cambio.

La etapa post-conciliar también conoció una postura de rechazo por parte de los conservadores quienes desde revistas y diversos libros manifestaban una crisis dentro de la Iglesia católica. Este sector del clero conservador está representado por el Opus Dei.

Esto se puede observar en la publicación de un artículo de L'Osservatore Romano el 2 de octubre de 1971. ¿Hasta qué punto se puede hablar de crisis dentro de la Iglesia? La Iglesia está pasando una etapa de afrontar y solucionar sus problemas. Esta postura viene de la jerarquía eclesiástica por mejorar el clima de discrepancias que han desatado las interpretaciones del concilio y la encíclica Populorum progressio. Según Nicolau (1972) las conferencias episcopales hablan de una crisis de fe, que ha sido calificada de preocupante generando una crisis de la oración, una crisis moral y una crisis de obediencia.

En la historia de la Iglesia ocurrieron crisis que permitieron afrontaron y analizar su misión. Esta nueva crisis que surgió luego del Vaticano II se debió a que el esfuerzo de renovación no fue acogido por un sector del clero. Los mandatos del Vaticano II eran a menudo tergiversados, no escapando la Iglesia y en general todos los cristianos de esta responsabilidad. Esta crisis enriqueció los debates postconciliares, logrando que de manera paulatina se vayan aplicando los mandatos conciliares en las diócesis de las diversas partes del mundo, incluido al Perú.

Lo que sí hubo fue un gran recelo por defender las posturas teológicas, llegando a contestaciones con la jerarquía eclesiástica. Además, se criticó fuertemente que la Iglesia se haya inclinado a lo suntuoso, dejando de lado la actitud crítica de no ser una Iglesia de los pobres.

La idea de una Iglesia de los pobres comienza con la conversión de quienes la conforman y viven de acuerdo al mensaje cristiano. Para ello, se necesita de paz y justicia que emanan del mensaje de Cristo en los evangelios, y aquellos documentos eclesiásticos durante toda la historia de la Iglesia.

\section{LOS MOVIMIENTOS SACERDOTALES DE LATINOAMÉRICA}

Los movimientos sacerdotales en Latinoamérica formaron parte de una generación de jóvenes sacerdotes latinoamericanos o europeos quiénes por vocación pusieron más atención a los sectores emergentes de las principales ciudades de los países latinoamericanos. El compromiso social de esta generación de sacerdotes se mostró en las luchas del pueblo para que puedan vivir en condiciones dignas y no infrahumanas. Dentro de los postulados de los diversos 
movimientos sacerdotales se hace un llamado a una revolución de estructuras (sociales, económicas y culturales), al despojo de todo privilegio, a la opción preferencial por los pobres y a la lucha de clases para llegar a una nueva sociedad libre y justa.

Al igual que el Movimiento Sacerdotal ONIS, los movimientos sacerdotales surgidos en Latinoamérica fundamentan sus planteamientos a partir del Vaticano II, Medellín, Populorum progressio, Pacen in terris y Mater et magistra. Las motivaciones de los diversos movimientos sacerdotales tenían como objetivo único el planteamiento de una nueva sociedad bajo los postulados del socialismo que no era tan discriminatorio y explotador como el capitalismo; ya que el capitalismo se basa en el lucro, mientras que el socialismo permite la intervención del Estado para llevar a cabo las reformas necesarias en bien de la sociedad y no de un limitado grupo que trata de mantener sus intereses de clase. Detrás de estos planteamientos se encuentra el trabajo pastoral desde las bases.

En esta investigación centraremos nuestra atención en los movimientos sacerdotales que surgieron en América del Sur, dejando de lado a los de América Central; esto no significa que su proceso sea diferente, más bien se asemeja al caso sudamericano. En Centroamérica podemos mencionar a "Sacerdotes para el Pueblo" de México y el "Movimiento Populorum Progressio" de Panamá.

Para entender el fenómeno religioso latinoamericano del compromiso con los sectores populares es necesario entender el impacto causado por el Vaticano II en Latinoamérica. La primera medida tomada por el clero tercermundista fue la declaración titulada "Mensaje de 18 Obispos del Tercer Mundo", que era el llamado que había hecho la encíclica Populorum progressio. Uno de los firmantes era Helder Camara que había participado en el concilio Vaticano II. Esta carta pastoral expresó el papel de los sacerdotes y fieles de los países subdesarrollados que luchaban por liberarse de la dependencia, miseria y atraso. Esta carta fue publicada en el 15 de agosto de 1967.

\subsection{Movimiento Sacerdotal para el Tercer Mundo (Argentina)}

Será en diciembre de 1967 cuando un grupo de sacerdotes progresistas de Argentina van a quedarse impactados y dar respuesta al "Mensaje de 18 Obispos del Tercer Mundo". Se reunirán en Santa Fe donde van a redactar una carta de apoyo al documento. Asimismo, el sacerdote Miguel Ramondetti, futuro secretario general del Movimiento Sacerdotal para el Tercer Mundo, viajó por todas las diócesis para recolectar firmas de adhesión llegando a sumar 400 firmas. Al final, dicha carta fue enviada a Helder Camara. Entre las conclusiones de dicho documento se menciona que el cristianismo no puede estar ausente de un proyecto político. El proyecto político debe ser el socialismo que libera de todas las dependencias, y los sacerdotes se comprometen a cumplir con dichas conclusiones (Noticias Aliadas, 1972, 46, Junio 14).

Los días 1 y 2 de mayo de 1968, en la ciudad de Córdoba, se llevó a cabo el I encuentro nacional de Sacerdotes para el Tercer Mundo. Se reunieron para discutir la carta de los obispos del Tercer Mundo. Finalizada la reunión, denunciaron públicamente las situaciones de injusticia y atraso, planteando como única solución: el socialismo.

En el II encuentro, en mayo de 1969 en la ciudad de Córdova, publicaron 
un documento titulado "Nuestras coincidencias básicas" donde se rechaza el sistema capitalista vigente de la época. En su tercer encuentro, en mayo de 1970, tocaron el tema del "peronismo", además de la publicación del documento que lleva por título "Comunicado de Santa Fe" en que afirmaron su fidelidad a la Iglesia y reiteraron su opción por el socialismo.

En noviembre de 1969, el general Juan Carlos Onganía consagra la nación argentina al Inmaculado Corazón de María. Por su parte, los sacerdotes para el Tercer Mundo manifiestan su "desconcierto e indignación"; más bien piden consagrar su compromiso y conductas para mejorar la sociedad.

Este movimiento tuvo un pronunciamiento El Movimiento Tercer Mundo de la Argentina y su opción por la liberación en que se definió por el socialismo; sin embargo, no era, ni quería, ni podía constituirse en "partido político" (NADOC, 1970, 147, Junio 3). La relación con la jerarquía no era buena; más bien, la jerarquía, en un documento del mes de agosto de 1970, se refería a este movimiento como "peligroso error que no debe continuar más".

\subsection{Grupo Golconda y Sacerdotes para América Latina (Colombia)}

En julio de 1968 se reunió un grupo de sacerdotes en la finca Golconda del municipio de Viotá, en Colombia, para reflexionar sobre el tema social a la luz de la Populorum progressio. Hubo una segunda reunión, en el mes de diciembre del mismo año, en la ciudad portuaria de Buenaventura. A esta segunda reunión asistió el obispo de Buenaventura, Mons. Gerardo Valencia Cano, que firmó junto a los sacerdotes una declaración denominada "Declaración de Golconda".
En el año de 1972 se reunieron diversos sacerdotes de Colombia, permitiendo de esta manera constituir el Movimiento SAL (Sacerdotes para América Latina).

Por otra parte, hubo en otros países manifestaciones sacerdotales denunciando las injusticias. Poco antes de la reunión de Medellín, tenemos el caso de Bolivia, donde un grupo de 86 sacerdotes se dirigió a sus obispos manifestando que "cada vez la Iglesia y el Mundo se encuentran más alejados". En Bolivia, la emisora radiofónica "Radio Pío XII" mantenía una línea revolucionaria en defensa de campesinos y mineros, pero fue intervenida por los militares en la madrugada del 26 de septiembre (NADOC, 1969, 108, Noviembre 19). En la tercera reunión del ISAL (Instituto Pastoral Andino) realizada el 23 de febrero de 1971, sus miembros manifestaron que "la participación de los cristianos en la lucha hacia el socialismo es cada vez mayor".

El logro que tuvieron los sectores progresistas de la Iglesia en Latinoamérica hizo que cada vez los sacerdotes asumieran un compromiso serio y radical, incluyendo la construcción de un "hombre nuevo" para una vía socialista. En Argentina se dieron grandes discusiones, represiones y asesinatos a sacerdotes. Mientras tanto, en el Perú no se daba tal caso, ya que el régimen militar no era tan represivo como en Argentina, Chile, Bolivia y Brasil.

\section{3 ¿Sacerdotes comunistas, marxistas o para una justicia social?}

El compromiso social que todo cristiano tiene con la realidad es objetivo, es decir, que la realidad en la cual se circunscribe necesita ser modificada para el bienestar común de la sociedad. El cristiano que no se siente 
identificado con su realidad es muy difícil que pueda asumir su compromiso con el prójimo. Esta expresión, sin embargo, tiene la crítica de que se aleja de la contemplación, para pasar al campo ideológico, especialmente al sector de la izquierda. En este punto abordaremos la temática que ha sido muchas veces tergiversada y que necesita ser comprendida bajo los parámetros de la ciencia histórica.

El compromiso con la sociedad, especialmente con los pobres, trae consigo muchas dificultades o críticas muy duras por parte de quienes tratan de mantener sus privilegios. Una de las críticas duras es manifestar que los sacerdotes que han luchado por una sociedad más justa son comunistas o marxistas. Inclusive la línea conservadora de la Iglesia postuló que la Teología de la Liberación no tendría nada que ofrecer luego de la caída del muro del Berlín en 1989. De esta manera, por inercia, la Teología de la Liberación decaería. Lo cierto es que la Teología de la Liberación no corresponde a la ideología marxista, comunista o socialista, sino a la visión cristiana que tiene como centro al pobre como criatura de Dios. Actualmente el margen entre pobres y ricos se va ampliando indefinidamente, $y$, el documento que permitía una Iglesia más comprometida con el factor social, político y económico es el de Medellín. Jon Sobrino, destacado teólogo jesuita, manifiesta que "la razón más importante, sin embargo, para volver a Medellín no es sólo formal, sino material: nuestra Iglesia y nuestro mundo, por ser un mundo de pobres, necesita imperiosamente de la Iglesia de los pobres que surgió en Medellín" (Alberigo, Sobrino, et al, 2002: 217). La Teología de la Liberación permitió profundizar la temática dada por Vaticano II.

La Iglesia en el Perú no es ajena a los acontecimientos que surjan en
América y Europa en materia teológica. La Iglesia es una, y de allí que toda postura o decisiones se vean reflejadas en la gran mayoría de los países. Si bien la Iglesia católica mantuvo una actitud de dominación durante cinco siglos en América Latina, su apertura hacia el mundo hizo que se viera como una "Iglesia nueva" cuyo rostro era el compromiso social.

En la constitución pastoral Gaudium et spes, remarca el asunto de la justicia social. Si bien esta constitución pastoral fue un paso profundo de la Iglesia en la sociedad, por otra parte hay quienes han visto en ella un peligro para la doctrina de la Iglesia.

Estas controversias, más ideológicas que pastorales, se darán luego del concilio Vaticano II, y, con más fuerza luego de salir publicada la encíclica Populorum progressio por Pablo VI. Para algunos comenzaba la etapa primaveral de la Iglesia, mientras que otros veían que la Iglesia se iría a la tumba por tomar esas posturas. Había cierto temor por parte de un sector de la Iglesia, ya que se pensaba que la Iglesia se secularizaría en su totalidad.

La Iglesia asumió una actitud de diálogo y de apertura, realizando planteamientos desde la metodología de las ciencias sociales, especialmente del marxismo que hace un análisis social y político de las realidades temporales. Si bien el planteamiento era utópico, se trataba de ir logrando una sociedad más justa.

Veamos algunas ideas al respecto:

El Movimiento Sacerdotal ONIS asumió la tesis de la lucha de clases no como la lucha o violencia contra una clase social, sino como la manera de mejorar la situación del pobre a la luz del evangelio. 
El P. Thomas Burns así lo expresa: "ONIS y las corrientes de la Teología de la Liberación nunca auspiciaron una lucha de clases; hay una lucha de clases y no hay que negarlo porque hay una injusticia social. Hay dos maneras de hacerlo: una, dialogando, llegando a tratar un acuerdo y, el otro, reclamando. Para la clase obrera, los sectores más pobres, es una lucha de defensa y no de agresión. La agresión viene de los que explotan y marginan. La lucha de clases quiere decir discrepancias y enfrentamientos verbales. La lucha de clases quiere decir levantar la cruz e ir contra la muerte para dar vida, y eso cuesta mucho" (Burns, T., comunicación personal, 19 de agosto de 2004).

¿A qué se debe la apertura del diálogo con marxistas o políticos de izquierda? La Iglesia necesitaba de instrumentos útiles para mejorar su análisis. Se necesitaba un diálogo abierto, pero esto no significa que se hiciera tabla rasa con la religión, sino que la religión y las ciencias sociales entraran en un solo camino.

¿Cómo plantean los cristianos los postulados de Marx? Según Plácido Diez y Ricardo Herrero, "para un creyente, la lectura de Marx es un esfuerzo continuo por ahondar en su convicción religiosa para presentarla al enfrentamiento, es una acuciante llamada a la verdad de nuestra religión a Dios. La crítica marxista de la religión no enferma la creencia cristiana, sino que la purifica" (Diez y Herrero, 1968: 29).

De esta manera, la crítica hecha por Marx no significa que la Iglesia sea afectada como institución, más bien se trata de mejorarla para que sea partícipe de su verdadero compromiso. ¿Qué se espera del marxismo? Según Plácido Diez y Ricardo Herrero "el marxismo no es cólera, sino esperanza y estímulo. Esperamos de él muchas realizaciones de largo alcance para el bien del mundo y para la total liberación del hombre. No lo soportamos como un fenómeno que nació al margen de la Iglesia y que debemos contemplar como una mera constatación histórica. Lo consideramos como un factor del actual pluralismo con el que debemos contar y que puede ofrecer una posibilidad de confrontación en dos niveles: como crítica del cristianismo y como realización del marxismo" (1968: 33).

El marxismo, para Plácido Diez y Ricardo Herrero, no es una religión ni un sistema antirreligioso, más bien es un programa de redención social que es inherente al "hombre religioso".

Si bien los lineamientos marxistas, comunistas o cristianos tienen por objetivo una sociedad más justa, pero a su vez una sociedad justa requiere de libertad: "El hombre no puede entregarse al bien si no dispone de su libertad: de una libertad que nuestros contemporáneos tanto estiman y ensalzan con entusiasmo y no sin razón; sin embargo, mucha veces la fomentan de malas maneras, como si fuera una licencia para todo lo que agrada, incluso para el mal. La auténtica libertad es una espléndida señal de la divina imagen en el hombre, ya que Dios quiso dejar al hombre en manos de su propia decisión" (Gaudium et spes: $\mathrm{N}^{\circ} 17$ ). El comunismo plantea una dictadura del proletariado y el marxismo plantea una dictadura del obrero. El cristianismo plantea la libertad y la tolerancia. Podríamos decir que el cristianismo, en especial el catolicismo luego del Vaticano II, propone obras para el servicio de los más pobres, pero no deja de estar en diálogo con la sociedad moderna. Igualmente, la Gaudium et Spes señala: "la misión propia que Cristo confió a su Iglesia no pertenece al orden político, económico o social: el fin que le asignó es el orden religioso. Cuando 
se presenta alguna necesidad, según las circunstancias de lugar y tiempo, la Iglesia puede, o mejor dicho debe crear obras que estén al servicio de todos, principalmente al servicio de los necesitados, como las obras de misericordia y otras análogas. La Iglesia reconoce, además, todo lo que hay de bien en el dinamismo social moderno; especialmente su evolución hacia la unidad, el proceso de una sana socialización y de asociación civil y económica". ( $\left.N^{\circ} 42\right)$.

El cristiano debe asumir la construcción de un nuevo orden. Las exigencias del cristiano no se encuentran totalmente en las sacristías o en los hogares, más bien se encuentran fuera de ellas. Charbonneau sostiene: "Si nosotros, cristianos, no hacemos de nuestra sociedad una sociedad cristiana, de nuestra economía una economía humana, de occidente un mundo de justicia, habremos sido la causa del fracaso del evangelio. Y solidariamente seremos responsables delante de Dios" (1969: 674).

Además, Charbonneau sostiene una tercera vía que no es marxista ni capitalista. Esta tercera vía debe estar enmarcada por una filosofía humanista y puede tener peligros demagógicos y la falta de compromiso; por esto, debemos estar en constante vigilancia. Esta tercera vía no va a proponer la violencia como medio para una sociedad más justa sino estar conscientes de la justicia social.

Dentro del sector conservador, ya fueran religiosos o laicos, se hablaba de sacerdotes marxistas. Por su parte, Enrique Dussel, historiador de la Iglesia en Latinoamérica, en una entrevista manifestaba que los teólogos de la liberación no eran marxistas: "Yo diría claramente que no somos marxistas. Lo que ocurre es que el que se encuentra dentro de una actitud, a veces de dominación, parecería que se opone a un solo tipo de pensamiento que estaría contra él y que sería el marxismo. Es como quien divide al mundo entre Oriente y Occidente, y en 'oriente' pone al mundo socialista... la teología de la liberación piensa en los pobres, piensa que el hombre está fuera del sistema, que hay que jugarse por el pobre. Y, pensando así, parece para el que domina -para el que usufructúa la explotación de ese pobre como lo subversivo, como alguien que quiere desordenar; a veces como el anarquista, o al menos 'lo anárquico' que no se sabe dónde va". (Acebal, 1973, 5, Mayo).

La participación sacerdotal en la política no es adecuada según la doctrina de la Iglesia. Otros manifiestan la infidelidad de la misión del sacerdote por ganar simpatía con campesinos y obreros. En sí, la participación de sacerdotes y obispos es un llamado a insertarse en lo secular para velar por una sociedad justa, despertando en ellos un sentido del hombre nuevo como objetivo de la caridad irrenunciable.

La actitud del sector progresista de la Iglesia, en especial de los sacerdotes, fue la del compromiso y entrega fiel hacia los oprimidos. Ahora, quien hace un análisis desde el mundo académico de ese entonces tiene que tener en cuenta el paradigma dado por el marxismo, lo que no significa que aquellos sacerdotes fueran marxistas ni mucho menos comunistas. Hoy podemos afirmar, a la luz de la historia, que la constante lucha ideológica de la época cegó e impidió el cambio de opción social de la Iglesia.

\section{ONIS: DOCTRINA DE LA IGLESIA Y PRAXIS}

\subsection{Doctrina social de la Iglesia Católica}

Los diversos comunicados y declaraciones de ONIS se fundaban en 
la doctrina social de la Iglesia. Entre los documentos de la Iglesia, ONIS va a usar la Populorum progressio, Pacem in terris, Mater et magistra, el Vaticano II (especialmente la Constitución Gaudium et spes) y Medellín. Los documentos emitidos por la Iglesia peruana, como Justicia en el mundo (1971), y el documento de la 36 Asamblea Episcopal Peruana, serán también usados por ONIS.

Según Luis Pásara, "ONIS había abandonado definitivamente el lenguaje del desarrollo para hacer suyo el de liberación" (1986:49). Esto se debió al esquema inicial de Gustavo Gutiérrez que disertaría sobre la teología del desarrollo, pero después mudó la propuesta teológica para asumir como eje la liberación de los menos favorecidos. Este planteamiento fue expuesto en julio de 1968 en la ciudad de Chimbote. El cambio implicó una postura radical en el plano teológico y, a su vez, una postura desde la realidad, ya que la sociedad peruana aún mantenía muchas características del sistema colonial.

Pero, ¿cuál ha sido la relación de ONIS con la Iglesia del Perú? Para el P. Felipe Zegarra, "ONIS nunca ha roto con la Iglesia a diferencia de otros grupos cuyas relaciones por lo menos fueron muy tensas. Me refiero a las experiencias Argentina y de Chile, muy cercanas a nosotros en muchas posiciones, pero de mayor conflicto con el obispado; ya he dicho que nosotros teníamos obispos que eran miembros de ONIS, y el cardenal Landázuri, si tuvo alguna inquietud probablemente la tuvo; nunca llamó al orden ni nada por el estilo" (Zegarra, F., comunicación personal, 29 de junio de 2005).

Por consiguiente, el Movimiento Sacerdotal ONIS mantenía una línea al interior de los planteamientos doctrinales de la Iglesia. La cercanía de miembros de ONIS a la jerarquía de la Iglesia peruana le permitió mantenerse en diálogo constante. Más bien, la acusación de desviaciones doctrinales provino de sectores conservadores.

\subsection{Praxis de ONIS}

Ante los cambios realizados por la Iglesia peruana, ONIS no va mostrarse paternalista. Más bien se mostró con una actitud seria de compromiso con la justicia social "que es un grito valiente de rebelión contra la injusticia social... que atrae necesariamente a los hombres de buena voluntad" (Fernández, 1956: 160). Las estructuras de opresión han de ser reducidas y los hombres deben gozar de la igualdad ante Dios y sus semejantes.

El tema de una sociedad más justa ya se venía hablando el año de 1959 en la primera semana social, y, luego, en la segunda de 1962. La primera fue llevada a cabo en Lima y la segunda en Arequipa. Además, el documento del episcopado peruano, Los católicos y la política, desarrolla el tema del bien común. La Iglesia fue desarrollando esta inquietud de manera paulatina, llegando a ser cada vez más consciente de la realidad peruana. Un ejemplo fue la medida adoptada por el cardenal Landázuri, quien por propia iniciativa dejó la residencia del episcopado ubicada en el distrito oligárquico de San Isidro para trasladarse al distrito de clase media de La Victoria, específicamente en la Urbanización Santa Catalina (La Prensa, 1969, marzo 6). La Iglesia católica comenzó a desprenderse de su actitud oligárquica. Esta forma de desprendimiento también se venía realizando en muchos países. Otro ejemplo fue la medida tomada por el jesuita Luis Bambarén, quien junto a sus hermanos transfirieron la propiedad de un fundo heredado para beneficio de 
los campesinos (Noticias Aliadas, 1969, setiembre 20).

Sin embargo, faltaba una postura más solidaria y comprometida con los obreros y campesinos. La población peruana veía en ONIS como parte de la "Iglesia nueva". Si bien dentro del clero había cierta disconformidad con este sector del clero progresista, quienes manifestaban su apoyo eran los campesinos y obreros que veían una Iglesia comprometida con su realidad, logrando que el mensaje cristiano fuera parte de su realidad. (Cox, 1985: 94-101)

La relación de ONIS con el cardenal Landázuri fue cordial y dialogante, pues éste asumía la justicia social y que la Iglesia no es ajena a los problemas de la sociedad, especialmente a los menos favorecidos. El cardenal llegó a respaldar la "Declaración de sacerdotes peruanos sobre las estructuras socio-económicas del país", que fueron las conclusiones finales de ONIS en su primera reunión. A comparación de otros movimientos sacerdotales, ONIS se mantenía en estrecha relación con la jerarquía peruana, es decir, "evitó los enfrentamientos directos con los obispos" (Klaiber, 1996: 401). Dentro de la documentación de ONIS con respecto a su relación con la jerarquía, se observa un absoluto trabajo con obispos. La participación de ONIS en diversos actos parecía ser para la nueva voz de la Iglesia progresista peruana, haciendo numerosos pronunciamientos y actividades solidarias.

ONIS planteaba una nueva forma de ser Iglesia. A pesar de las discrepancias y tensiones, no discrepaba con personas. Francisco Chamberlain declara que "discrepancias con personas no las hubo. Evidentemente ONIS planteaba una nueva manera de ser Iglesia y esto puede que haya creado tensiones con otras maneras de pensar. Ciertamente el conflicto no fue en esos años, hablo de los años de 1970 hasta prácticamente la muerte del cardenal Landázuri, porque Landázuri era un hombre creo de sentimientos básicamente conservadores, pero con capacidad también para respetar las diferentes opciones, orientaciones legítimas dentro de la Iglesia. La Iglesia no es un cuartel, o sea, puede haber diferencias teológicas y diferentes orientaciones de tipo pastoral y el hecho que uno discrepe con ONIS u ONIS discrepe con uno, no quiere decir que uno va a estar dentro y el otro fuera de la Iglesia" (Comunicación personal, 26 agosto de 2004).

El sector del clero que participaba dentro de ONIS era un porcentaje muy pequeño en relación con el clero peruano en general. Según Michael Macaulay, de un total de 2162 sacerdotes del clero peruano, los participantes de ONIS fueron 203; es decir, ONIS representaba aproximadamente al $9.4 \%$ del clero nacional. De todos los participantes de ONIS el $38.4 \%$ era peruano de nacimiento; es decir, que los integrantes en su mayoría eran extranjeros, destacando sacerdotes de nacionalidad estadounidense con un 23.2\% (Macaulay, 1972: 72). En consecuencia, se ha tratado de decir que ONIS no tenía una membresía básicamente nacional y que el clero extranjero tenía mayor número de participantes. Si bien los sacerdotes extranjeros no conocían bien el idioma castellano, esto no era óbice para brindar sus servicios a los más pobres (ÁlvarezCalderón, comunicación personal, 27 de setiembre de 2003).

\subsection{El Movimiento Sacerdotal ONIS tuvo dos etapas:}

Dentro de las actividades de ONIS puede establecerse una clasificación 
atendiendo a su postura eclesial o social. La primera postura es eclesial (19681971) y busca una renovación del clero. La segunda postura es social (1971 1975), donde se pone énfasis en la vía socialista. Luego de la publicación del texto Teología de la Liberación en el año de 1971, ONIS va a dejar la postura eclesial para entrar en el campo social. Además de ambas posturas, ONIS intentaba una revolución de las estructuras sociales existentes, ya que la gran mayoría de la población vivía en condiciones deplorables.

La primera postura de la periodificación se explica porque al inicio ONIS tenía que hacer valer sus propuestas ante el clero peruano, ya que gran parte del clero era de tendencia conservadora. Los sacerdotes de ONIS desarrollaban su labor pastoral en las distintas jurisdicciones de la Arquidiócesis de Lima, especialmente en los sectores alejados, donde se iniciaban las barriadas.

Los sacerdotes peruanos que trabajaban con los sectores populares eran escasos, siendo Jorge ÁlvarezCalderón y Gustavo Gutiérrez los pocos ejemplos de sacerdotes peruanos que trabajaban en parroquias de los sectores populares de Lima, ya que quienes en su mayoría trabajaban en las zonas populares eran sacerdotes extranjeros. Este gran número de sacerdotes extranjeros se debía a la necesidad de sacerdotes en Latinoamérica.

La segunda postura denominada "social" no es estrictamente una ruptura con la eclesial, sino más bien un reforzamiento de la misma apoyándose en los postulados de la doctrina católica latinoamericana para tomar una postura de compromiso contra las estructuras de dominación y de opresión. Con la publicación de Teología de la Liberación se tuvo un sustento teológico que fue asumido por este movimiento $\mathrm{y}$ otros movimientos sacerdotales en Latinoamérica. ONIS asumió sus planteamientos teológicos, los que le servirían para su participación con las bases en asuntos políticos. A su vez, insistía en el modelo socialista para una sociedad nueva, pero sin dejar lo eclesial.

A continuación, presentamos un cuadro que nos permite observar las acciones del Movimiento Sacerdotal ONIS. 


\begin{tabular}{|c|c|c|}
\hline DOCUMENTO & Fecha & Tema Central \\
\hline $\begin{array}{l}\text { Declaración sobre la crisis } \\
\text { que vive el país }\end{array}$ & $\begin{array}{l}20 \text { de } \\
\text { septiembre de } \\
\mathbf{1 9 6 8}\end{array}$ & $\begin{array}{l}\text { La cuestión petrolera de La Brea y } \\
\text { Pariñas tiene causas en la deplorable } \\
\text { consciencia moral de los gobernantes. }\end{array}$ \\
\hline $\begin{array}{l}\text { Declaración sobre la } \\
\text { reforma agraria }\end{array}$ & $\begin{array}{l}20 \text { de junio de } \\
\mathbf{1 9 6 9}\end{array}$ & $\begin{array}{l}\text { La reforma agraria debe tener } \\
\text { como centro al campesino, no } \\
\text { por el marco jurídico, sino por su } \\
\text { dignidad humana. El Estado debe } \\
\text { dar asistencia educativa, técnica y } \\
\text { crediticia al campesino, además de } \\
\text { evitar el monopolio de los productos } \\
\text { manufacturados de la tierra. }\end{array}$ \\
\hline $\begin{array}{l}\text { Declaración ante los } \\
\text { problemas laborales }\end{array}$ & $\begin{array}{c}22 \text { de enero de } \\
\mathbf{1 9 7 0}\end{array}$ & $\begin{array}{l}\text { Los problemas laborales se dan por } \\
\text { causa de la sociedad capitalista que } \\
\text { tiene como fin el lucro, debiendo ser } \\
\text { sustituida por una nueva estructura } \\
\text { asumida por los sectores populares. }\end{array}$ \\
\hline $\begin{array}{l}\text { Declaración sobre } \\
\text { el presente de la } \\
\text { transformación nacional }\end{array}$ & $\begin{array}{l}\text { febrero-mayo de } \\
\mathbf{1 9 7 0}\end{array}$ & $\begin{array}{l}\text { La transformación social del Perú } \\
\text { debe tener como ideología el } \\
\text { reconocimiento del hombre como } \\
\text { ser libre y social. }\end{array}$ \\
\hline $\begin{array}{l}\text { El sismo del } 31 \text { de mayo } \\
\text { y la consciencia cristiana }\end{array}$ & $\begin{array}{l}15 \text { de julio de } \\
\mathbf{1 9 7 0}\end{array}$ & $\begin{array}{l}\text { En este documento de ONIS-Norte } \\
\text { se hace un llamado a solidarizarse } \\
\text { con quienes han perdido todo. Se } \\
\text { debe realizar una reforma urbana } \\
\text { para que quienes tienen escasos } \\
\text { recursos accedan a una vivienda } \\
\text { digna. }\end{array}$ \\
\hline $\begin{array}{l}\text { No reconstruyamos la } \\
\text { injusticia }\end{array}$ & $\begin{array}{l}27 \text { de julio de } \\
\mathbf{1 9 7 0}\end{array}$ & $\begin{array}{l}\text { Una "nueva sociedad" debe ser } \\
\text { un medio de realización personal } \\
\text { y comunitaria. Se debe forjar una } \\
\text { nueva mentalidad que permita que } \\
\text { las clases populares sean agentes } \\
\text { activos por una sociedad más justa. }\end{array}$ \\
\hline $\begin{array}{l}\text { Propiedad privada y } \\
\text { nueva sociedad }\end{array}$ & $\begin{array}{c}15 \text { de agosto de } \\
\mathbf{1 9 7 0}\end{array}$ & $\begin{array}{l}\text { La propiedad privada debe dar } \\
\text { paso a la propiedad social, para la } \\
\text { creación de una nueva sociedad. }\end{array}$ \\
\hline $\begin{array}{l}\text { Declaración a propósito } \\
\text { del problema magisterial }\end{array}$ & $\begin{array}{c}4 \text { de septiembre } \\
\text { de } \mathbf{1 9 7 1}\end{array}$ & $\begin{array}{l}\text { Ante los cambios emprendidos en el } \\
\text { sector educativo, se pide austeridad } \\
\text { económica en los gastos que se } \\
\text { vienen realizando para el proyecto, } \\
\text { ya que el proceso revolucionario } \\
\text { debe beneficiar a los sectores } \\
\text { populares. }\end{array}$ \\
\hline
\end{tabular}




\begin{tabular}{|c|c|c|}
\hline $\begin{array}{l}\text { Declaración de ONIS- } \\
\text { Norte ante la situación } \\
\text { de los trabajadores en las } \\
\text { cooperativas agrarias de } \\
\text { producción }\end{array}$ & $\begin{array}{l}7 \text { de marzo de } \\
\mathbf{1 9 7 2}\end{array}$ & $\begin{array}{l}\text { La mentalidad patronal no permite que } \\
\text { la reforma agraria cumpla su principal } \\
\text { objetivo: la participación de la clase } \\
\text { trabajadora en la administración. }\end{array}$ \\
\hline $\begin{array}{l}\text { Declaración con motivo } \\
\text { de la visita del general } \\
\text { Hugo Bánzer a Lima. }\end{array}$ & $\begin{array}{l}19 \text { de julio de } \\
\mathbf{1 9 7 3}\end{array}$ & $\begin{array}{l}\text { Se pone en claro que la llegada } \\
\text { del general Hugo Bánzer a Lima } \\
\text { es repudiable ya que su gobierno } \\
\text { significa el impedimento del proceso } \\
\text { de liberación del pueblo boliviano. }\end{array}$ \\
\hline $\begin{array}{l}\text { Solidaridad con Chile (En } \\
\text { este documento también } \\
\text { firma el Mov. Fe y Acción } \\
\text { Solidaria) }\end{array}$ & $\begin{array}{l}18 \text { de } \\
\text { septiembre de } \\
\mathbf{1 9 7 3}\end{array}$ & $\begin{array}{l}\text { El documento se adhiere a la } \\
\text { protesta internacional por los } \\
\text { maltratos y persecuciones del } \\
\text { gobierno militar chileno. }\end{array}$ \\
\hline $\begin{array}{l}\text { Comunicado Trabajo } \\
\text { Humano y Propiedad } \\
\text { Social }\end{array}$ & $\begin{array}{c}20 \text { de octubre de } \\
\mathbf{1 9 7 3}\end{array}$ & $\begin{array}{l}\text { Se insta a la creación de una sociedad } \\
\text { nueva y la pronta construcción de } \\
\text { una sociedad desinteresada. }\end{array}$ \\
\hline $\begin{array}{l}\text { Comunicado sobre la } \\
\text { expropiación de diarios }\end{array}$ & $\begin{array}{c}3 \text { de agosto de } \\
\mathbf{1 9 7 4}\end{array}$ & $\begin{array}{l}\text { Los medios de comunicación tienen } \\
\text { que llegar a ser una permanente } \\
\text { creación y anuncio del hombre } \\
\text { nuevo y una sociedad nueva. }\end{array}$ \\
\hline Carta sobre Andahuaylas & $\begin{array}{c}15 \text { de octubre de } \\
\mathbf{1 9 7 4}\end{array}$ & $\begin{array}{l}\text { Manifestar el repudio a quienes } \\
\text { emplean la violencia contra el } \\
\text { pueblo campesino marginado y } \\
\text { oprimido que reclama las tierras } \\
\text { para vivir y trabajar. }\end{array}$ \\
\hline $\begin{array}{l}\text { Comunicado sobre } \\
\text { la situación política y } \\
\text { exigencias evangélicas }\end{array}$ & $\begin{array}{c}23 \text { de febrero de } \\
\mathbf{1 9 7 5}\end{array}$ & $\begin{array}{l}\text { Sobre la situación de los campesinos } \\
\text { de Andahuaylas. La situación política } \\
\text { es de una fuerte represión contra } \\
\text { quienes buscan un espacio donde vivir } \\
\text { dignamente. Análisis de la situación } \\
\text { política a la luz del evangelio. }\end{array}$ \\
\hline $\begin{array}{l}\text { Comunicado sobre las } 28 \\
\text { deportaciones decretadas } \\
\text { el } 6 \text { de agosto y que luego } \\
\text { fueron dejadas sin efecto }\end{array}$ & $\begin{array}{c}11 \text { de agosto de } \\
\mathbf{1 9 7 5}\end{array}$ & $\begin{array}{l}\text { Llamado a la defensa de la libertad } \\
\text { y de justicia para las organizaciones } \\
\text { campesinas y de prensa. }\end{array}$ \\
\hline $\begin{array}{l}\text { Pronunciamiento de } \\
\text { ONIS-Norte: recusación } \\
\text { cristiana al festival de la } \\
\text { primavera }\end{array}$ & $\begin{array}{l}21 \text { de } \\
\text { septiembre de } \\
\mathbf{1 9 7 5}\end{array}$ & $\begin{array}{l}\text { Se rechaza la celebración eucarística } \\
\text { para el "Festival de la primavera" que } \\
\text { se llevará a cabo en la Catedral de } \\
\text { Trujillo. También los actos que van } \\
\text { en contra la dignidad de la mujer. }\end{array}$ \\
\hline
\end{tabular}


La praxis de ONIS también se veía en los encuentros que tenía para analizar el desarrollo de sus actividades como las coordinaciones que sean necesaria para analizar la situación del pobre a la luz del Evangelio.

\begin{tabular}{|c|c|c|c|}
\hline & Lugar & Fecha & Tema Central \\
\hline Inicio de ONIS & Cieneguilla & $\begin{array}{l}\text { Inicios de } \\
\text { marzo de } 1968\end{array}$ & $\begin{array}{l}\text { "La problemática económico, } \\
\text { social y política del país". }\end{array}$ \\
\hline $\begin{array}{l}\text { I Encuentro } \\
\text { Nacional }\end{array}$ & Chimbote & $\begin{array}{l}\text { Del } 21 \text { al } 25 \text { de } \\
\text { julio de } 1968\end{array}$ & $\begin{array}{l}\begin{array}{l}\text { Ahondar } \\
\text { problemática }\end{array} \\
\text { social y político. }\end{array}$ \\
\hline $\begin{array}{l}\text { II Encuentro } \\
\text { Nacional }\end{array}$ & Santa Anita & $\begin{array}{l}\text { Del } 30 \text { de } \\
\text { septiembre al } \\
4 \text { de octubre } \\
\text { de } 1969\end{array}$ & $\begin{array}{l}\text { "La Iglesia en el Perú de hoy. } \\
\text { Evaluaciones y perspectivas" }\end{array}$ \\
\hline $\begin{array}{l}\text { III Encuentro } \\
\text { Nacional }\end{array}$ & Huachipa & $\begin{array}{l}\text { Del } 9 \text { al } 14 \text { de } \\
\text { noviembre de } \\
1970\end{array}$ & Concientización y evangelización. \\
\hline $\begin{array}{l}\text { No hubo encuentro. } \\
\text { Tan sólo reunión. }\end{array}$ & Ñaña & $\begin{array}{l}\text { Del } 11 \text { al } 14 \\
\text { de noviembre } \\
1971\end{array}$ & La política y trabajo pastoral.. \\
\hline $\begin{array}{l}\text { IV Encuentro } \\
\text { Nacional }\end{array}$ & Huachipa & $\begin{array}{l}\text { Del } 9 \text { al } 14 \text { de } \\
\text { octubre de } \\
1972\end{array}$ & $\begin{array}{l}\text { El desempeño de las diversas } \\
\text { regiones de ONIS ante su } \\
\text { labor pastoral. }\end{array}$ \\
\hline
\end{tabular}

En conclusión, el caminar de la iglesia Católica en el Perú post Vaticano II se vio envuelta en orientar la labor pastoral hacia la justicia social, además, provocó una eclosión de los sectores progresistas en Latinoamérica. La nueva generación de sacerdotes que llegaron de Europa a fines de 1950 e inicios de 1960 trajeron un nuevo paradigma: el sacerdote no debe ocuparse tan sólo del culto religioso, sino también del aspecto social. En Latinoamérica hubo enfrentamientos de sacerdotes con la jerarquía eclesiástica o el gobierno de turno, como son los casos de Argentina, Brasil, Chile, Colombia, y Bolivia. El caso peruano fue particular, ya que el régimen militar tenía planteamientos reformistas. ONIS en su inicio se encargaba de informar al clero peruano de la problemática social y económica del país. Para determinar su dirección como agrupación se convocó a un I encuentro nacional (julio de
1968), donde surgió como Movimiento Sacerdotal. La labor pastoral realizada por el P. Jorge Álvarez-Calderón fue de orientar a los sectores populares hacia la justicia social. ONIS se esforzó en defender los intereses de las clases populares, ya que su opción por los pobres les exigía trabajar para que tuvieran condiciones de vida digna. Al defender los intereses de los sectores populares fueron vistos como sacerdotes subversivos o marxistas por parte del sector conservador de la Iglesia.

\section{REFERENCIAS:}

ADOLFS, Robert (1967). La tumba de Dios. Buenos Aires: Carlos Lohlé.

AGUIRRE, Jesús et. al (1969). Cristianos y marxistas. Madrid: Alianza Editorial. 
ALBERIGO, Giuseppe (Ed.). (1993). Historia de los concilios. Salamanca: Sígueme.

ALBERIGO G., Sobrino J., et al. (2002) Teología de la Liberación. Cruce de miradas. Lima: Centro de Estudios y Publicaciones - Instituto Bartolomé de las Casas.

BARAUNA, Guillermo. (1967). La Iglesia en el mundo de hoy. Estudios y comentarios a la Gaudium et spes del concilio Vaticano II. Madrid: Studium.

BRANDT, Richard (Comp.) (1965). Justicia social. México: Limusa Wiley. 2da Edición.

Centro de Estudios y Publicaciones (Comp.) (1989) Irrupción y caminar de la Iglesia de los pobres. Presencia de Medellín. Lima: CEP- IBC.

CHARBONNEAU, P. E. (1969). Cristianismo, sociedad y revolución. Salamanca: Sígueme.

CEHILA (1987) Historia general de la Iglesia en América Latina. T VIII. Salamanca: Sígueme.

CONCILIO VATICANO II (1986). Documentos completos. Bilbao: Mensajero.

COX, Harvey (1985). La religión en la ciudad secular. Hacia una teología postmoderna. Santander: Sal Terrae.

DALMA, Joseph (1971). Agonía del autoritarismo católico. Barcelona: Ariel.

DIEZ ALEGRÍA, José María (1967). Actitudes cristianas ante los problemas sociales. Roma: Estela.
DIEZ PLÁCIDO y HERRERO-VELARDE, Ricardo (1968). Revolución marxista y progreso cristiano. Barcelona: Nova terra.

DUSSEL, Enrique (Comp.) (1995). Resistencia y esperanza: historia del pueblo cristiano en América Latina y El Caribe. Costa Rica: Departamento Ecuménico de Investigaciones.

FERNÁNDEZ DE CASTRO, Ignacio (1956) Del paternalismo a la justicia social. Madrid: Euroamérica.

GARLAND, Alfredo (1978). Como lobos rapaces. Lima: Atlántida.

GIRARDI, Jules (1971). Amor cristiano y lucha de clases. Salamanca: Sígueme.

GUICHARD, Jean (1973). Iglesia, lucha de clases y estrategias políticas. Salamanca. Sígueme.

GUTIÉRREZ, Gustavo (1981). Teología de la Liberación. Lima: CEP.

KLAIBER, Jeffrey (1980). Religión y revolución en el Perú. 1824-1976. Lima: Universidad del Pacífico.

KLAIBER, Jeffrey (1996). La Iglesia en el Perú: su historia social desde la independencia. Lima: PUCP. 3 era. Edic.

LOPEZ OLIVA, Enrique (1970). Los católicos y la revolución latinoamericana. La Habana: Ciencias Sociales

MIRET MAGDALENA, Enrique (1966) Los nuevos católicos. Barcelona: Nova Terra. 
MOVIMIENTO DE SACERDOTES PARA EL TERCER MUNDO (1971) ¿Qué son los sacerdotes para el tercer mundo? Buenos Aires.

MUCKENHIM, Carlos (1969). Exigencias de renovación. Bilbao: Mensajero.

NICOLAU, Miguel (1972) La crisis de la Iglesia. Criterio de Renovación. Madrid: BAC.

PÁSARA, Luis (1986) Radicalización y conflicto en la Iglesia Peruana. Lima: El Virrey.

RAMÍREZ AGUILAR, Juan (2013) En torno a la reforma Católica del siglo XVI. En Rosas Moscoso, Fernando (Comp.) Historia de la Civilización. Aproximaciones al proceso histórico del sistema capitalista (siglos XIIIXXI), (179-188), Lima: Editorial universitaria

RIGA, Peter (1968) Iglesia y revolución. España: Sal Terrae.

ROMERO, Catalina (1987) La Iglesia en el Perú. Compromiso y renovación (1958-1984). Lima: IBC-Rímac.

VELA, Carlos (1968). Doctrina social post-conciliar. Madrid: Selecciones gráficas.

\section{ARTÍCULOS}

ACEBAL MONFORT, Luis (1973). Iglesia y desarrollo en América Latina ¿Son marxistas los teólogos de la liberación? Entrevista con Enrique Dussel. Sal Terrae. 61 (5), 384-388.

BENAVIDES, Gustavo (1988). Poder político y religión en el Perú. Márgenes. 4. 21-54.
GIRARDI, Jules (1968). Filosofía de la revolución y ateísmo. Concilium. 3436, 505-519.

GONZALES-CARBAJAL, Luis (2004). El concilio Vaticano II, 40 años después. Sal Terrae. 1074. 67-81.

GUCHTENEERE, Pedro de (1997)."Un hito en el pensamiento social. Nota a los 30 años de la Populorum progressio. Páginas 144, 69-70.

MOLINA, Diego (2004). Iglesiamundo: una relación cambiante. Sal Terrae. 1075, 163-174.

PÁSARA, Luis (1983). De militante católico a militante de izquierda. Debate. 20, 29 - 33 .

RAMÍREZ AGUILAR, Juan (2004). La Teología de la Liberación y su aporte renovador. Historia Total. 1, 165-174.

SOBRINO, Jon (1998). Vigencia de la teología de la liberación. Páginas, 151, 91-98.

\section{FUENTES INÉDITAS:}

Centro de Estudios y Publicaciones (1970). Declaraciones y mensajes a partir del sismo (mimeógrafo). Lima: CEP.

Centro de Estudios y Publicaciones (1970). Movimiento Sacerdotal ONIS. Declaraciones marzo 1968-mayo 1970. Lima: CEP.

Centro de Estudios y Publicaciones (1973). Signos de liberación. Testimonios de la Iglesia en América Latina 1969-1973. Lima: CEP.

Conferencia Episcopal De Acción Social (1969). Signos de renovación. 
Recopilación de documentos postconciliares de la Iglesia en América Latina (1966 1969) Lima: CEAS.

Conferencia Episcopal Peruana (1961) Los católicos y la política. Carta pastoral del Episcopado del Perú a los sacerdotes y fieles. Lima: Sesator.

Conferencia Episcopal Peruana (1959). Exigencias sociales del catolicismo en el Perú. Lima: S/E

Juan XXIII (1962). Pacem in terris. Lima: Paulinas-Salesiana.

\section{FUENTES ORALES:}

Comunicación personal de Jorge Álvarez-Calderón. 27-9.2003.

Comunicación personal de Luis Fernando Crespo. 22 -6 2004.

Comunicación personal de Tomas Burns. 22-8-2004.

Comunicación personal de Francisco Chamberlain. 26-8-2004.

\section{FUENTES SECUNDARIAS}

\section{TESIS}

Jun Jo, Young (2003). El papel del grupo sacerdotal ONIS en la transformación social y eclesial peruana durante el periodo del gobierno militar de Velasco Alvarado: 1968-1975. Tesis presentada a la UNAM para obtener el grado de maestro en estudios latinoamericanos.

Macaulay, Michael (1972). Ideological change and internal cleavages in the Peruvian church: change, status quo and the priest: The case of ONIS. Tesis presentada a la Universidad de Notre Dame para obtener grado de doctor en filosofía. EE.UU.

Rienzo M, Gregorio (1970). Pensamiento social en la Iglesia católica de América Latina a partir de la encíclica Populorum Progressio: evaluaciones y proyecciones. Tesis presentada a la UNMSM para obtener el grado de bachiller en Sociología. Lima.

\section{PERIÓDICOS}

El Comercio 1968-1975.

La Prensa 1968-1975.

Expreso 1968 1975.

Correo 1972.

\section{REVISTAS}

Páginas 1972 - 1975.

Oiga 1968-1975.

Caretas 1968-1975.

\section{FOLLETOS Y DOCUMENTOS ECLESIALES}

Noticias Aliadas Documentación: NADOC. T. I (Oct. 1968-Jun. 1969).

Noticias Aliadas Documentación: NADOC. T. II (Jul 1969-Dic 1969).

Noticias Aliadas Documentación: NADOC. T. III (En. 1970-Jun. 1970).

Noticias Aliadas Documentación: NADOC. T. IV (Jul 1970-Dic 1970).

Noticias Aliadas Documentación: NADOC. T. V (En. 1971-Dic 1971).

Noticias Aliadas Documentación: NADOC. T. VI (En. 1972-Dic. 1972) 
